\title{
Article \\ pH-Responsive Chitosan/Alginate Polyelectrolyte Complexes on Electrospun PLGA Nanofibers for Controlled Drug Release
}

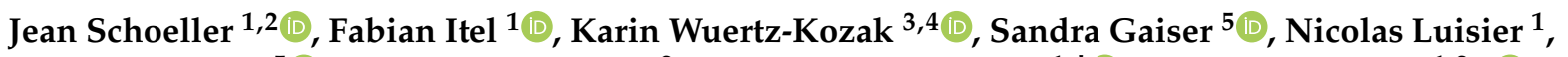 \\ Dirk Hegemann ${ }^{5}$, Stephen J. Ferguson ${ }^{2}$, Giuseppino Fortunato ${ }^{1,+}+(i)$ and René M. Rossi ${ }^{1,2, *(i)}$ \\ 1 Empa, Swiss Federal Laboratories for Materials Science and Technology, Laboratory for Biomimetic \\ Membranes and Textiles, 9014 St. Gallen, Switzerland; jean.schoeller@empa.ch (J.S.); \\ fabian.itel@empa.ch (F.I.); nicolas.luisier@gmail.com (N.L.); giuseppino.fortunato@empa.ch (G.F.) \\ 2 Institute for Biomechanics, ETH Zürich, 8093 Zürich, Switzerland; sferguson@ethz.ch \\ 3 Schoen Clinic Munich Harlaching, Spine Center, Academic Teaching Hospital and Spine Research Institute of \\ the Paracelsus Medical University Salzburg (AU), 81547 Munich, Germany; kwbme@rit.edu \\ 4 Department of Biomedical Engineering, Rochester Institute of Technology (RIT), Rochester, NY 14607, USA \\ 5 Empa, Swiss Federal Laboratories for Materials Science and Technology, Laboratory for Advanced Fibers, \\ 9014 St. Gallen, Switzerland; sandra.gaiser@empa.ch (S.G.); dirk.hegemann@empa.ch (D.H.) \\ * Correspondence: rene.rossi@empa.ch \\ + This author passed away in June 2020 .
}

\section{check for}

updates

Citation: Schoeller, J.; Itel, F.; Wuertz-Kozak, K.; Gaiser, S.; Luisier,

N.; Hegemann, D.; Ferguson, S.J.;

Fortunato, G.; Rossi, R.M.

pH-Responsive Chitosan/Alginate

Polyelectrolyte Complexes on

Electrospun PLGA Nanofibers for

Controlled Drug Release.

Nanomaterials 2021, 11, 1850. https://

doi.org/10.3390/nano11071850

Academic Editor: Margaret Frey

Received: 1 June 2021

Accepted: 7 July 2021

Published: 17 July 2021

Publisher's Note: MDPI stays neutral with regard to jurisdictional claims in published maps and institutional affiliations.

Copyright: (c) 2021 by the authors. Licensee MDPI, Basel, Switzerland. This article is an open access article distributed under the terms and conditions of the Creative Commons Attribution (CC BY) license (https:// creativecommons.org/licenses/by/ $4.0 /)$.
Abstract: The surface functionalization of electrospun nanofibers allows for the introduction of additional functionalities while at the same time retaining the membrane properties of high porosity and surface-to-volume ratio. In this work, we sequentially deposited layers of chitosan and alginate to form a polyelectrolyte complex via layer-by-layer assembly on PLGA nanofibers to introduce $\mathrm{pH}$ responsiveness for the controlled release of ibuprofen. The deposition of the polysaccharides on the surface of the fibers was revealed using spectroscopy techniques and $\zeta$-potential measurements. The presence of polycationic chitosan resulted in a positive surface charge $(16.2 \pm 4.2 \mathrm{mV}, \mathrm{pH} 3.0)$ directly regulating the interactions between a model drug (ibuprofen) loaded within the polyelectrolyte complex and the layer-by-layer coating. The release of ibuprofen was slowed down in acidic $\mathrm{pH}$ (1.0) compared to neutral $\mathrm{pH}$ as a result of the interactions between the drug and the coating. The provided mesh acts as a promising candidate for the design of drug delivery systems required to bypass the acidic environment of the digestive tract.

Keywords: electrospinning; pH-responsive; drug delivery; surface functionalization; layer-by-layer; natural polymers; surface charge; oral delivery

\section{Introduction}

Electrospinning is a powerful technique to produce non-woven fibrous meshes from polymer solutions or polymer melts. Electrospun nanofibers present several advantages such as high surface-to-volume $(S / V)$ ratio and high porosity. Furthermore, the design of responsive electrospun nanofibers has drawn significant attention in the past decade due to their ability to undergo physical or chemical changes when subjected to different stimuli. Such stimuli include $\mathrm{pH}$, temperature, light, and electrical and magnetic fields [1-4]. "Smart" responsive nanofibers have found applications for biomedical purposes as scaffolds for tissue engineering, drug delivery systems, biosensors, and wound dressings [5-14]. When considering drug delivery, $\mathrm{pH}$ responsiveness has been widely investigated, especially for the design of systems providing a targeted and controlled release of active pharmaceutical ingredients. Indeed, $\mathrm{pH}$-responsive systems can overcome biological barriers by restricting the release to certain $\mathrm{pH}$ values and therefore preventing systemic exposure of the drug to the patient due to the different $\mathrm{pH}$ environments within the human body. For the development of responsive drug delivery systems, nanofibers have shown great potential compared to other planar substrates. Mainly due to their high 
permeability and porosity, nanofibers have proven to provide shorter response times to environmental changes and therefore better control over the drug release [15].

When designing drug delivery platforms, one must consider the biocompatibility and biodegradability of the materials used, as such systems are developed to integrate different cellular environments and thus are likely to degrade over time. Poly(lactic-coglycolic acid) (PLGA, Figure 1A) has proven to be a suitable material due to its wellknown biocompatibility and biodegradability [16]. Natural polymers have also emerged as excellent candidates for drug delivery systems. For this purpose, alginate (ALG, Figure 1C), a water-soluble anionic polysaccharide, is used for numerous biomedical applications thanks to its biocompatibility, biodegradability, and non-toxicity [17-19]. Furthermore, chitosan (CHI, Figure 1B), an abundant linear polysaccharide of deacetylated $\beta-1,4-\mathrm{D}-$ glucosamine, has been widely used in the past decade for its unique properties [20]. In fact, chitosan is one of the only natural cationic polymers containing primary amines in its polymeric backbone. Therefore, the assembly of $\mathrm{CHI}$ in solution is highly dependent upon protonation of the amino group $(\mathrm{pKa} \approx 6.1)$. Once the amino function gets protonated, the polymeric backbone of chitosan becomes charged, leading to charge repulsion and swelling [21-24]. CHI and ALG form polyelectrolyte complexes in solution or on surfaces due to their oppositely charged polymeric backbones [25]. Such polyelectrolyte complexes are known to provide better mechanical and chemical stability than the isolated compounds while retaining their $\mathrm{pH}$-sensitive behavior $[17,26,27]$.

A<smiles>CC(C)OC(=O)COC(C)(C)OC(C)C(=O)O</smiles>

$E$

\section{B}

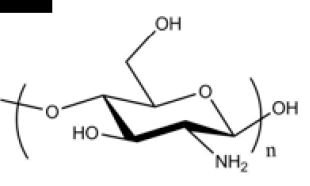

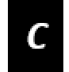
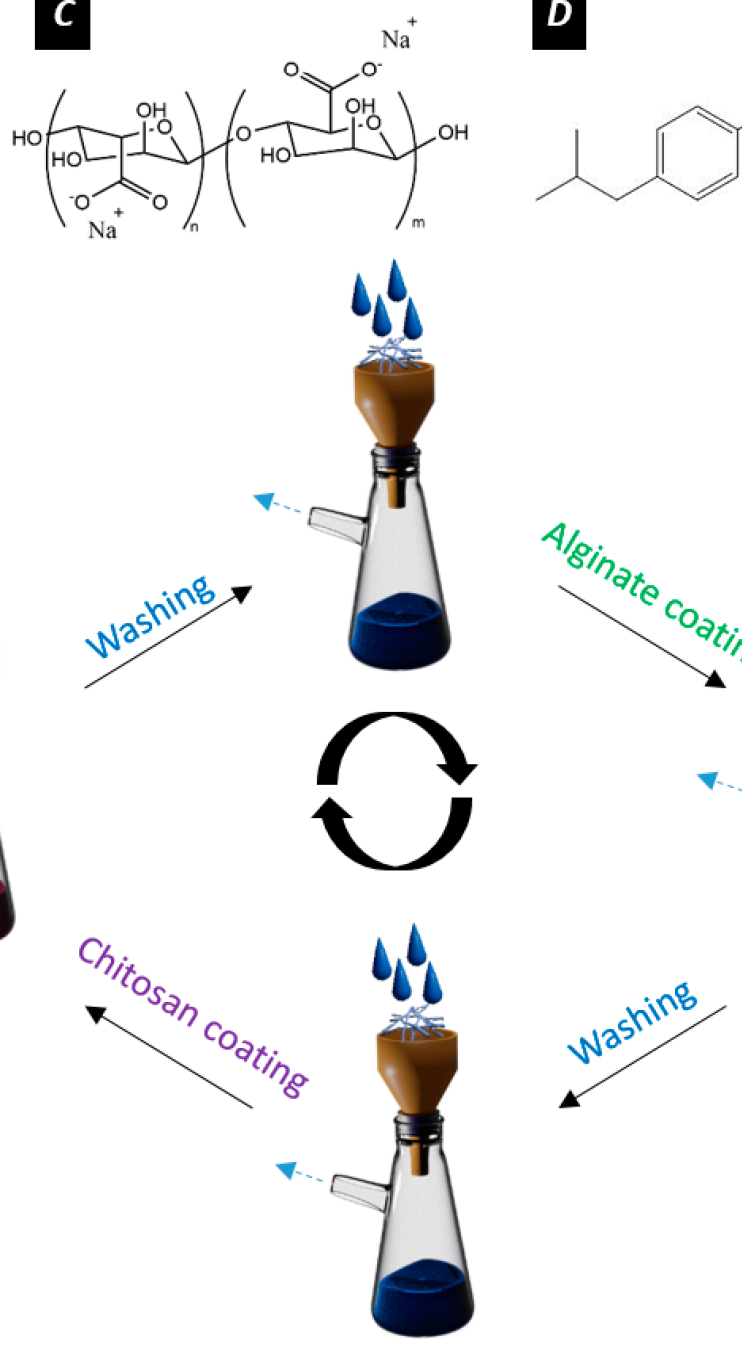

$\boldsymbol{D}$<smiles>CC(C)Cc1ccc(C(C)C(=O)O)cc1</smiles>

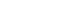

PLGA nanofibers
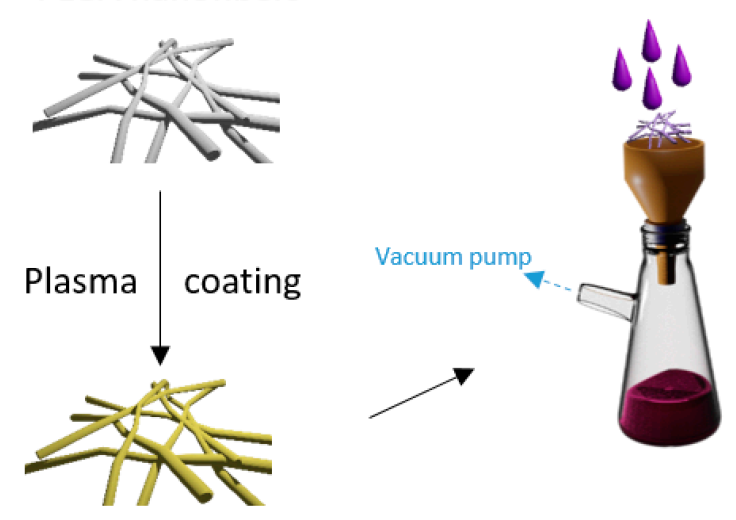

Figure 1. Chemical structures of (A) PLGA, (B) chitosan, (C) alginate, and (D) ibuprofen. (E) Summary of the LbL process for functionalizing the fibers. In this study, alginate and chitosan layers were alternatively deposited on the surface of plasma-coated electrospun nanofibers. The alginate and chitosan solutions are depicted in green and purple, respectively. 
Electrospinning has been widely studied in the past decades, with a recent focus on the potential of surface modifications to achieve more sophisticated nanofibrous systems $[28,29]$. This can be achieved via crosslinking, coating, or chemical modifications of electrospun nanofibers $[7,28]$. For polymer coatings, layer-by-layer assembly (LbL) has proven to be a robust, versatile, and reproducible method for the grafting of polymers onto surfaces using electrostatic interactions [30-35]. LbL exploits the charges of the polymeric backbone of polymers to favor interactions with an oppositely charged polymer in order to deposit a thin layer over the surface. Nanofibers show great potential for this technique due to their high surface-to-volume ratio. Several groups have studied the feasibility of LbL on electrospun nanofibers. For example, using LbL-inspired techniques, Lin et al. coated poly(lactic acid) electrospun nanofibers with chitosan [29]. The coated fibers exhibited a better crystallization of calcium phosphate, thus making the system a potential candidate for bone tissue engineering. Moreover, Croisier et al. have grafted $\mathrm{CHI}$ onto the surface of electrospun poly( $\varepsilon$-caprolactone) fibers to provide anti-bacterial properties to the overall system [36]. In another study, Wang et al. developed a vascular

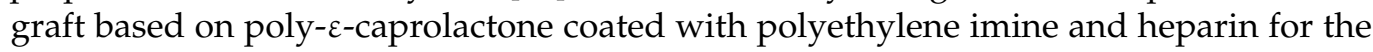
sustained delivery of epigallocatechin gallate [32]. In addition, Deng et al. have deposited CHI/ALG polyelectrolyte complexes on the surface of cellulose nanofibers [37]. The fibers exhibited better cell growth than the pristine fibers. Although several studies have revealed the capacity of electrospun nanofibers to act as substrates for the deposition of polymeric layers via LbL, no reports were made about the evaluation of such systems for $\mathrm{pH}$-sensitive drug release. Nevertheless, this technique can act as a versatile approach to tailor loading and release kinetics.

Here, we investigate the ability of polyelectrolyte-coated PLGA nanofibers to release ibuprofen (IBU, Figure 1D) in response to environmental changes in $\mathrm{pH}$. After incorporating negative charges via plasma coating onto the surface of PLGA nanofibers, we sequentially deposited the desired number of layers of CHI and ALG using LbL. Then, the specimens were characterized to study the deposition of the polymeric layers onto the surface of the fibers. Ibuprofen served as a model drug and was loaded onto the coating. The influence of the number of layers on the loading efficiency as well as the release kinetics with alterations in $\mathrm{pH}$ was highlighted. Figure $1 \mathrm{E}$ summarizes the process used for LbL coatings. The choice of material properties, combining oppositely charged polymers, control over layer thickness, and thus diffusion properties, as well as $\mathrm{pH}$ sensitive units make this approach highly versatile for the controlled loading and delivery of drugs. Clearly distinguished drug release kinetics at neutral $\mathrm{pH}$ (7.4) compared to an acidic $\mathrm{pH}(1.0)$ allow for tuned drug delivery in response to the environment. Thereby, drug-loaded electrospun membranes are protected from drug release in the acidic environment of the stomach and reach their target of higher environmental $\mathrm{pH}$ without previous loss and reduced drug concentration. In the future, this will help to bypass side effects with drug release at non-specified sites and help to fine-tune the host and target specific therapies. In this study, we show the applicability of LbL coatings on the surface of electrospun nanofibers for the design of $\mathrm{pH}$-sensitive drug delivery systems.

\section{Materials and Methods}

Materials: PLGA with a ratio of 50/50 lactic acid to glycolic acid (Resomer RG505, inherent viscosity $0.73 \mathrm{dL} \cdot \mathrm{g}^{-1}$, molecular weight of $54-69 \mathrm{kDa}$ ) was bought from Evonik Technology GmbH, Essen, Germany. Chitosan (medium molecular weight, 190-310 kDa), sodium alginate, anhydrous tetrahydrofuran (THF), ibuprofen (IBU), and benzyltriethylammonium chloride (BTEAC) were bought from Sigma-Aldrich (Sigma-Aldrich, Buchs, Switzerland) and used as received. $N, N$-dimethyl formamide (DMF) was purchased from Sigma-Aldrich (Sigma-Aldrich, Switzerland) and dried over molecular sieves (4A) prior to use. All the water used in this study was Milli- $\mathrm{Q}^{\circledR}$ water (Veolia, Basel, Switzerland).

Preparation of PLGA electrospun nanofibers: An in-house built electrospinning setup, as previously reported, was used for the fabrication of PLGA electrospun nanofibers [38]. 
PLGA was dissolved in a solvent system of $85 / 15 \%(v / v)$ THF/DMF to achieve a final polymer concentration of $15 \%(w / v)$. BTEAC was added to the solution at a concentration of $0.1 \%(w / v)$. A syringe equipped with a $0.456 \mathrm{~mm}(21 \mathrm{G})$ diameter needle was filled with the polymer solution and loaded on a syringe pump. The polymer solution was emitted at a rate of $20 \mu \mathrm{L} \cdot \mathrm{min}^{-1}$ under a potential difference of $20 \mathrm{kV}(+15 /-5 \mathrm{kV})$ with a needle-to-collector distance of $20 \mathrm{~cm}$ on a rotating drum $(50 \mathrm{rpm})$ covered with aluminum foil. The membranes were electrospun for $4 \mathrm{~h}$. Then, the mats were dried overnight in a vacuum oven at $40{ }^{\circ} \mathrm{C}$. To assess the morphological properties of the electrospun nanofibers, the specimens were coated with $8 \mathrm{~nm}$ Au/Pd (EM ACE600, Leica Microsystems, Opfikon, Switzerland) and analyzed using an S-4800 scanning electron microscope (Hitachi HighTechnologies, Schaumburg, IL, USA). The average diameter of the nanofibers was measured using ImageJ (ImageJ2, USA) [39]. For each specimen, $n=50$ random measurements were performed on a total number for each picture per condition. (Figures S1 and S2).

Plasma coating of PLGA electrospun nanofibers: In order to introduce an oxygen-containing functional hydrocarbon layer onto the surface of the electrospun nanofibers, an ultrathin plasma coating ( $\leq 20 \mathrm{~nm}$ ) was used as described in previous reports [40-42]. The coating comprises a vertical chemical gradient by changing the power and gas flow rate during the plasma deposition process in order to enhance adhesion, stability, and surface functionality [43]. Briefly, the electrospun nanofibers were introduced in a radio frequency-driven plasma chamber with a power input of $70 \mathrm{~W}$, a pressure of $0.1 \mathrm{mbar}$, and exposed to a mixture of $8 \mathrm{sccm}$ of carbon dioxide $\left(\mathrm{CO}_{2}\right)$ with $4 \mathrm{sccm}$ of ethylene $\left(\mathrm{C}_{2} \mathrm{H}_{4}\right)$ for $190 \mathrm{~s}$. Afterwards, the power was lowered to $30 \mathrm{~W}$ while the $\mathrm{CO}_{2}$ gas flow rate was increased to $24 \mathrm{sccm}$ for another $50 \mathrm{~s}$ of plasma exposure. The plasma-coated meshes were kept under vacuum in a desiccator prior to further usage.

Polyelectrolyte complex deposition via layer-by-layer assembly: Then, plasma-coated electrospun nanofibers were coated with $\mathrm{CHI}$ and ALG. CHI was dissolved for $48 \mathrm{~h}$ in $0.8 \%$ $(v / v)$ acetic acid to achieve a final concentration of $0.1 \%(w / v)$, while ALG was dissolved for $48 \mathrm{~h}$ in water at a concentration of $0.1 \%(w / v)$. Both solutions were adjusted to $\mathrm{pH} 5$ with $0.1 \mathrm{M} \mathrm{HCl}$. Nanofibrous meshes were cut into $50 \mathrm{~mm}$ diameter circles $(\approx 100 \mathrm{mg})$ and placed on a Büchner filter membrane. Then, $50 \mathrm{~mL}$ of the $\mathrm{CHI}$ solution was suctioned through the mesh under vacuum for each side of the mesh. Afterwards, membranes were washed three times with $150 \mathrm{~mL}$ of MilliQ water on each side of the meshes to remove excess CHI from the surface. Then, a layer of ALG was added using the same procedure for the coating and washing. This process was repeated until a desired number of layers was obtained $(5,9$, and 15$)$. Finally, the membranes were dried at $40{ }^{\circ} \mathrm{C}$ in a vacuum oven. The coated nanofibers were kept under vacuum before further characterization. The meshes with 5, 9, or 15 layers are referred to as $(\mathrm{CHI} / \mathrm{ALG})_{5},(\mathrm{CHI} / \mathrm{ALG})_{9}$, and $(\mathrm{CHI} / \mathrm{ALG})_{15}$.

X-ray photoelectron spectroscopy: A LS5600 X-ray photoelectron spectroscope (Physical Electronics, Chanhassen, MN, USA) was used to assess the chemical environment of the surface of the nanofibrous meshes. The spectrometer was equipped with a standard Al-K $\alpha$ source, and the resolution was set to $0.8 \mathrm{eV}^{-s_{e}} \mathrm{p}^{-1}$ at a pass energy of $187.85 \mathrm{eV}$ for survey scans and $0.25 \mathrm{eV}$ at a pass energy of $46.15 \mathrm{eV}$ for region scans. The acceleration voltage and current of the X-ray beam were set to $13 \mathrm{kV}$ and $15 \mathrm{~mA}$, respectively. Casa XPS (Casa Software Ltd., Teignmouth, UK) was used for data analysis, whereas carbon $1 S$ was used for the calibration of the spectra at $284.5 \mathrm{eV}$.

$\zeta$-potential measurements: The $\zeta$-potential of the electrospun meshes was measured in response to the $\mathrm{pH}$, in a range of 3 to 9 , using a Surpass 3 electro-kinetic flow through a $\zeta$-potential meter (Anton Paar, Graz, Austria). A pulsating stream of electrolyte solution ( $1 \mathrm{mM} \mathrm{KCl}$ in MilliQ water) was generated along the membrane to shear off the double layer, thus allowing the measurement of a streaming potential. The membranes were first rinsed 3 times with the electrolyte solution at the respective $\mathrm{pH}$ prior to the measurement.

Infrared spectroscopy: Attenuated Total Fourier Transform Infrared (AT-FTIR) spectra were recorded with a Varian 640-IR FTIR (Agilent Technologies, Santa Clara, CA, USA) 
on the sample surface. For each specimen, spectra were recorded at a range of 500 to $4000 \mathrm{~cm}^{-1}$ with a spectral resolution of $1 \mathrm{~cm}^{-1}$.

Drug loading: To study the kinetics of the loading from the electrospun constructs in response to $\mathrm{pH}, \mathrm{IBU}$ was used as a model drug. For loading the drug, the meshes $(5.4 \pm 1.9 \mathrm{mg})$ with different numbers of polysaccharide layers were immersed in $2 \mathrm{~mL}$ of a saturated solution of IBU in MilliQ water $\left(0.021 \mathrm{mg} \cdot \mathrm{mL}^{-1}\right)$ at $\mathrm{pH} \mathrm{2.0,5.0,7.0,} \mathrm{and} \mathrm{10.0.}$ At specific time points $(15 \mathrm{~m}, 30 \mathrm{~m}, 1 \mathrm{~h}, 2 \mathrm{~h}, 4 \mathrm{~h}, 6 \mathrm{~h}, 8 \mathrm{~h}$, and $10 \mathrm{~h}), 30 \mu \mathrm{L}$ of the solution was collected and replaced with $30 \mu \mathrm{L}$ of fresh water solution of the same $\mathrm{pH}$. Then, the collected supernatants were diluted to achieve a final volume of $500 \mu \mathrm{L}$, which is the minimum volume required for Ultra High-Performance Liquid Chromatography (UHPLC) measurements. To quantify the amount of drug entering the mesh, an Acquity UHPLC (Waters Inc., Baden, Switzerland) equipped with a UV-vis detector was used. Separation was achieved by reverse-phase gradient elution from $95 / 5 \%$ to $5 / 95 \%(v / v)$ water/acetonitrile over $5 \mathrm{~min}$. The mobile phase was delivered at a flow rate of $0.5 \mathrm{~mL} \cdot \mathrm{min}^{-1}$ through an Acquity ${ }^{\circledR} \mathrm{C} 18$ column $(2.1 \times 50 \mathrm{~mm}, 1.7 \mu \mathrm{m})$. The detector wavelength was set at $221 \mathrm{~nm}$, and the injection volume was $15 \mu \mathrm{L}$. Calibration curves using standard concentrations of IBU for the different $\mathrm{pH}$ values were recorded and used for quantification using the MassLinx ${ }^{\circledR}$ interface. A typical chromatogram for IBU, the integration parameters, and the calibration curves for all the experiments can be found in Figures S3-S5 as well as Table S1. For further experiments, the specimens were immersed in a saturated solution of ibuprofen at $\mathrm{pH} 2.0$ for $1 \mathrm{~h}$ and further washed two times with MilliQ water. The amount of drug lost during the washing steps was taken into account for further experiments.

Release experiments: After loading the meshes at the $\mathrm{pH}$ offering the highest loading capacity, the release of IBU was evaluated at $37^{\circ} \mathrm{C}$ in phosphate-buffered saline (PBS) solution at pH 5.5 and 7.4 as well as in simulated gastric fluid (SGF, $\mathrm{NaCl} 2 \mathrm{~g} \cdot \mathrm{L}^{-1}, \mathrm{pH} 1.0$ ). For this purpose, similar strips $(6.0 \pm 2.1 \mathrm{mg})$ of the loaded samples were immersed in $3 \mathrm{~mL}$ of each buffer solution. At specific time points $(30 \mathrm{~m}, 1 \mathrm{~h}, 1 \mathrm{~h} 30 \mathrm{~m}, 2 \mathrm{~h}, 4 \mathrm{~h}, 12 \mathrm{~h}$, $24 \mathrm{~h}, 48 \mathrm{~h}$, and $72 \mathrm{~h}$ ), $300 \mu \mathrm{L}$ of the supernatant were collected and replaced with $300 \mu \mathrm{L}$ of fresh buffer solution to keep the volume of the release media constant at $3 \mathrm{~mL}$. Then, the collected supernatants were diluted to $500 \mu \mathrm{L}$ and quantified using the aforementioned UHPLC method.

The release curves were fitted with a Ritger-Peppas model according to the equation:

$$
\frac{M_{t}}{M_{\infty}}=K t^{n}
$$

where $M_{\infty}$ is the amount of drug at the equilibrium state, $M_{t}$ is the amount of drug released over time (amount of drug loaded), $K$ is the release velocity constant, and $n$ is the exponent of release [44-46].

Statistical analysis: Results are displayed as mean \pm standard deviation. Based on the small sample size, no normal distribution could be assumed. Therefore, statistical significance was assessed by a Kruskal-Wallis test for the groups followed by pairwise comparison with the Dunn test (Bonferroni corrections), and results were accepted as significantly different for $p<0.05$. All the tests were performed in $\mathrm{R}$, and the $p$-values mentioned in the text are the adjusted values [47].

\section{Results}

\subsection{Preparation and Characterization of the Electrospun Nanofibers \\ 3.1.1. Electrospinning}

PLGA electrospun nanofibers were successfully prepared. While the electrospinning of PLGA produced fibers in the micron scale, adding salt (BTEAC) to increase the conductivity of the solution resulted in fibers in the nanoscale range, with an average diameter of $547 \pm 105 \mathrm{~nm}$. The fibers were homogeneous and bead-free, as depicted in Figure 2A. 


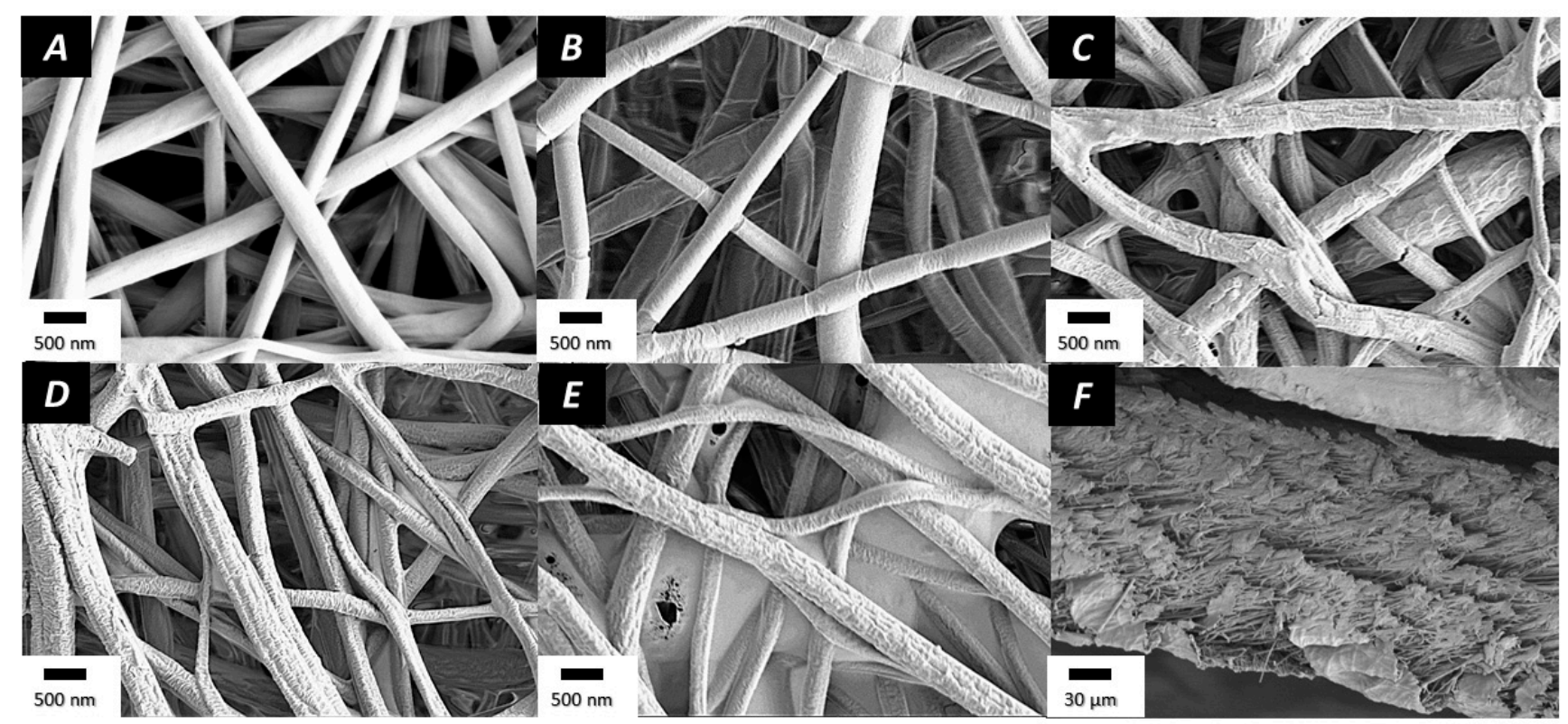

Figure 2. SEM pictures of (A) PLGA nanofibers, (B) plasma-coated nanofibers, (C) (CHI/ALG) 5 , (D) (CHI/ALG) (E) $(\mathrm{CHI} / \mathrm{ALG})_{15}$, and (F) cross-section of $(\mathrm{CHI} / \mathrm{ALG})_{15}$ layers.

\subsubsection{Plasma Coating and Layer-by-Layer Assembly}

To introduce negative charges over the surface of pristine PLGA electrospun nanofibers, the fibers were submitted to a radio-frequency plasma gradient to lower the charge of the mesh [48]. The morphology and the diameter of the fibers remained unchanged by the plasma coating, and the resulting nanofibers had an average diameter of $539 \pm 118 \mathrm{~nm}$ (Figure 2B). After grafting the CHI/ ALG polyelectrolyte complex, the surface of the electrospun fibers became granular (Figure 2). The average diameter of the fibers did not change significantly and was $550 \pm 124 \mathrm{~nm}, 545 \pm 109 \mathrm{~nm}$, or $547 \pm 137 \mathrm{~nm}$ for (CHI/ALG) $(\mathrm{CHI} / \mathrm{ALG})_{9}$, or $(\mathrm{CHI} / \mathrm{ALG})_{15}$, respectively (Figure $\left.2 \mathrm{C}-\mathrm{E}\right)$. The distribution of the diameters for 50 random measurements is shown in Figure S1. A cross-section of (CHI/ALG) 15 was also performed to study the inner layers of the mesh (Figure 2F). Furthermore, lower magnifications of the meshes to study the homogeneity of the coating can be found in Figure S2 and revealed the poor homogeneity of the deposition of the coating.

\subsubsection{Fourier-Transform Infrared Spectroscopy}

AT-FTIR spectroscopy was used to confirm the presence of CHI on the surface of the nanofibers (Figure 3). For pure PLGA nanofibers, a strong peak is observed between 1760 and $1750 \mathrm{~cm}^{-1}$, which is characteristic for carbonyl groups $(C=O)$. Another band is observed between 1300 and $1150 \mathrm{~cm}^{-1}$, corresponding to the ester $(\mathrm{O}=\mathrm{C}-\mathrm{O})$ groups of PLGA. After LbL coating, a broad band appeared at $3500 \mathrm{~cm}^{-1}$, corresponding to the amine and hydroxyl groups of CHI. Another peak at $1623 \mathrm{~cm}^{-1}$ appeared, corresponding to the $\mathrm{N}-\mathrm{H}$ of the amino function of $\mathrm{CHI}[27,49]$.

\subsubsection{X-ray Photoelectron Spectroscopy (XPS)}

X-ray photoelectron spectroscopy (XPS) was used to study the surface composition of the electrospun meshes (Figure 4). Pure PLGA nanofibers had the expected elemental composition as reported in the literature with the characteristic O1s peak at $533 \mathrm{eV}$ and $\mathrm{C} 1 \mathrm{~s}$ peak at $284.5 \mathrm{eV}$, thus confirming the carbon and oxygen elements of the PLGA polymer matrix [50]. The elemental composition revealed $60.0 \%$ carbon and $39.5 \%$ oxygen at the surface of the meshes (Figure $4 \mathrm{~A}$ ). The chemical environment revealed the typical peaks of $\mathrm{C} 1$ s corresponding to $\mathrm{O}=\mathrm{C}-\mathrm{O}(31.7 \%), \mathrm{C}=\mathrm{O}(33.3 \%) \mathrm{C}-\mathrm{C}$, and $\mathrm{C}-\mathrm{H}(35.0 \%)$ bonds at 288.3 , 286.4, and $284.5 \mathrm{eV}$, respectively (Figure 4D). After plasma coating (Figure 4B), the amount 
of $\mathrm{C} 1 \mathrm{~s}$ on the surface of the nanofibers increased to $72.9 \%$ and the O1s decreased to $28.8 \%$. When looking at the region scans (Figure 4E), the peak shape for $\mathrm{C} 1 \mathrm{~s}$ did not show the three characteristic peaks of PLGA anymore; however, a broader peak appeared. The peak fitting revealed the presence of $\mathrm{C}-\mathrm{O}(32.0 \%), \mathrm{C}=\mathrm{O}(20.6 \%), \mathrm{O}-\mathrm{C}=\mathrm{O}(12.1 \%), \mathrm{C}-\mathrm{C}$, and $\mathrm{C}-\mathrm{H}$ (35.4\%) bonds. After the grafting of the $\mathrm{CHI}$ and ALG layers (Figure 4C), a peak appeared at 396-404 eV, revealing the deposition of nitrogen on the surface of the nanofibers. The nitrogen content at the surface of the membrane was $5.2 \%, 4.8 \%$, or $5.2 \%$ for $(\mathrm{CHI} / \mathrm{ALG})_{5}$, $(\mathrm{CHI} / \mathrm{ALG})_{9}$, or $(\mathrm{CHI} / \mathrm{ALG})_{15}$, respectively. The spectra for ALG and CHI can be found in the Supporting Information (Figure S6).

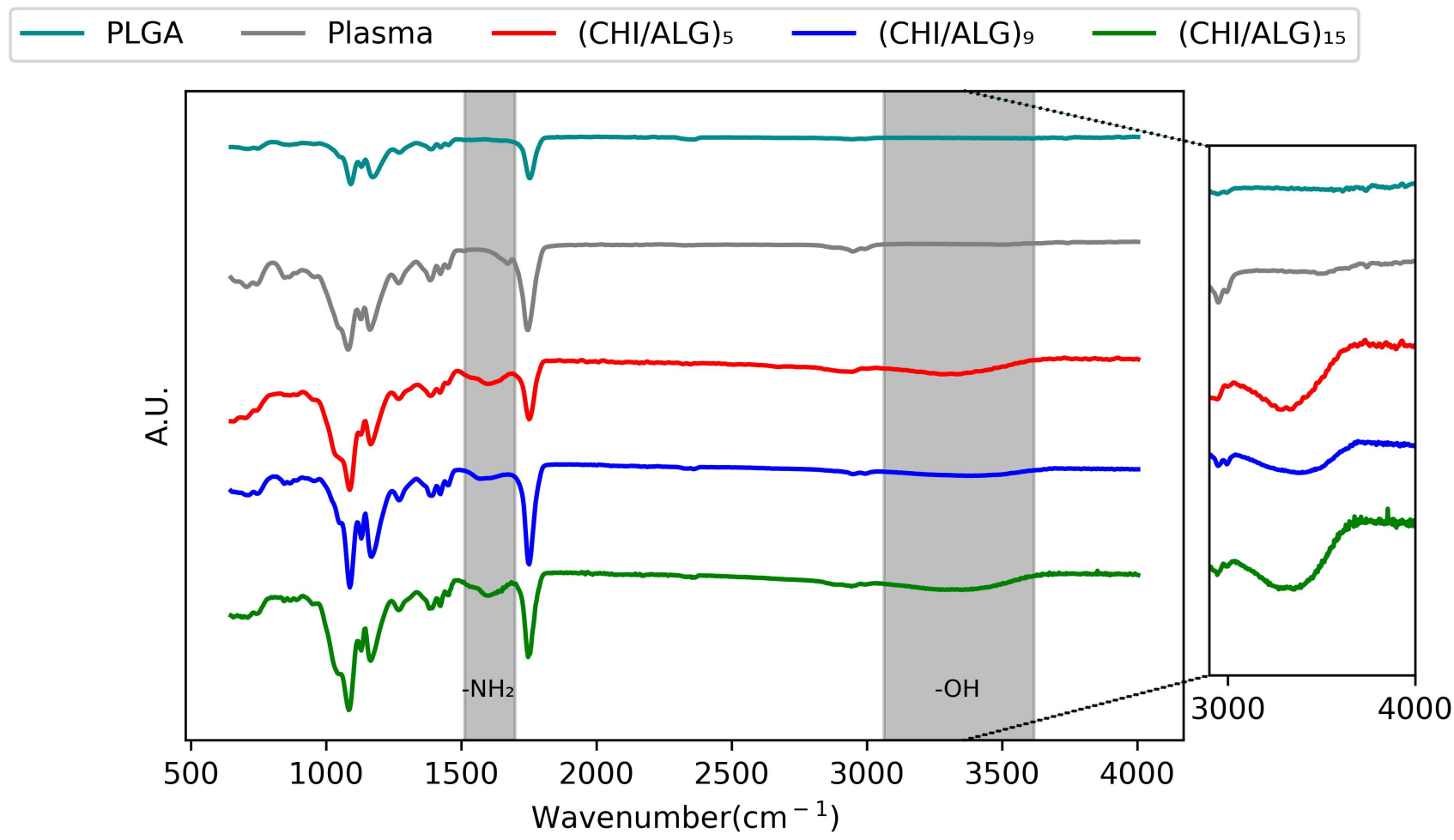

Figure 3. AT-FTIR of PLGA, plasma-coated, (CHI/ALG) $)_{5}(\mathrm{CHI} / \mathrm{ALG})_{9}$, and (CHI/ALG) ${ }_{15}$ electrospun nanofibers. The inset highlights the differences between the peaks in the $3000-4000 \mathrm{~cm}^{-1}$ region corresponding to the alcohol function present on both alginate and chitosan polymeric backbones. The region from 1550 to $1650 \mathrm{~cm}^{-1}$ describes the apparition of the amino function present in the chitosan polymeric backbone.

\subsection{5. ל-Potential Measurements}

To obtain a better understanding of the electrostatic forces involved during the LbL assembly, the surface $\zeta$-potential at each step of the coating was measured. Pure PLGA nanofibers showed a negative $\zeta$-potential over the range of $\mathrm{pH}$ measured $(-20.0 \pm 4.9 \mathrm{mV}$ at $\mathrm{pH}$ 5). After plasma coating, the $\zeta$-potential of the membranes generally decreased to lower values $(-38.3 \pm 7.4 \mathrm{mV}$ at $\mathrm{pH} 5)$. Furthermore, after the deposition of a first layer of $\mathrm{CHI}$ onto the surface, the $\zeta$-potential shifted to positive values in acidic $\mathrm{pH}$ (Figure 5A), but after depositing a layer of ALG, the $\zeta$-potential of the meshes returned to lower values (Figure 5B) while remaining positive. 

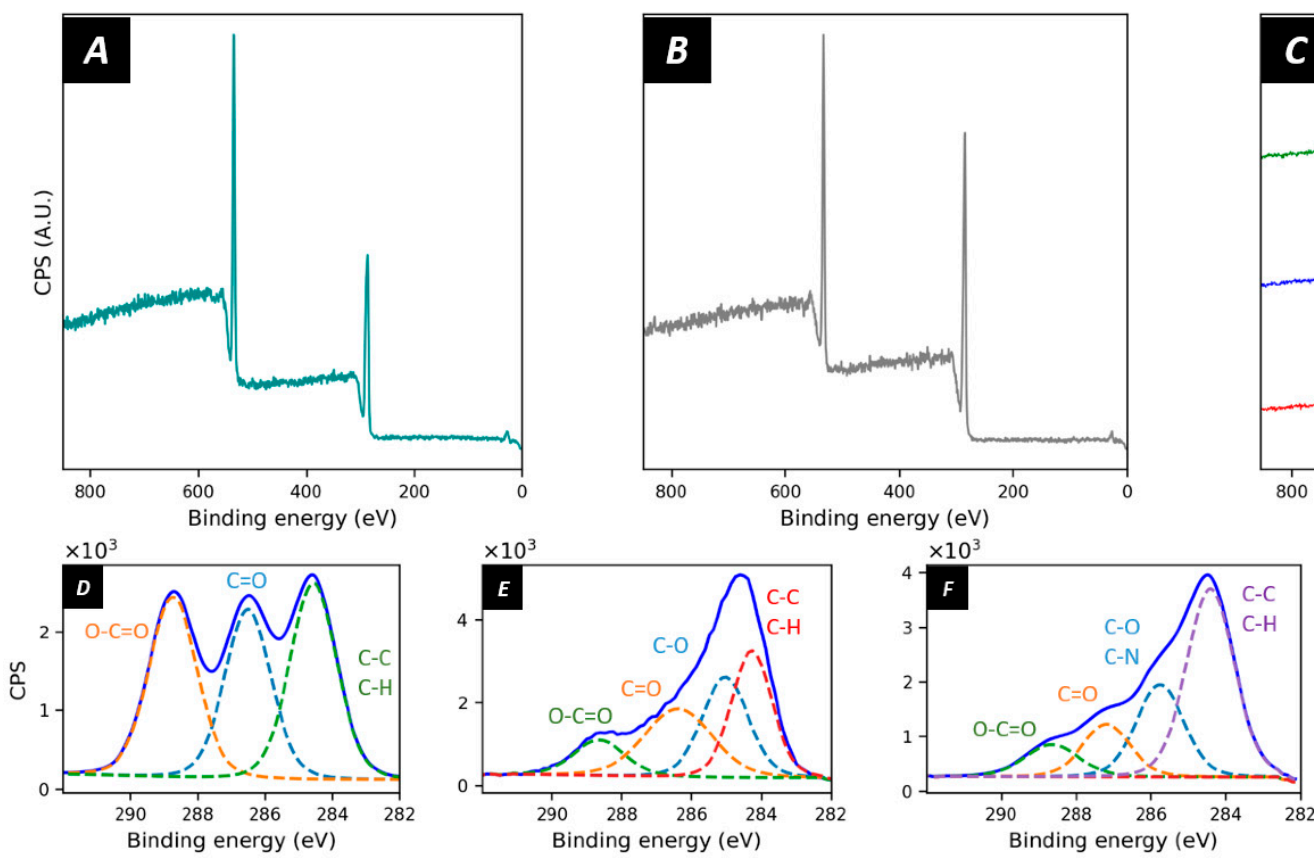

$-(\mathrm{CHI} / \mathrm{ALG})_{5}-(\mathrm{CHI} / \mathrm{ALG})_{9} \quad-(\mathrm{CHI} / \mathrm{ALG})_{15}$

Figure 4. XPS survey scans of (A) PLGA, (B) plasma-coated PLGA, (C) (CHI/ALG) 5 , (CHI/ALG) latter demonstrates a succesful deposition of chitosan due to the apparition of the typical peaks at 396-404 eV, depicting the presence of nitrogen onto the surface of the meshes. The region scans for (D) C1s of PLGA, (E) C1s of plasma-coated PLGA, and $(\mathrm{F}) \mathrm{C}(1 \mathrm{~s})$ of $(\mathrm{CHI} / \mathrm{ALG})_{5}$ show the chemical changes on the surface throughout the different steps of the coating. The region scan for $(\mathrm{G}) \mathrm{N} 1 \mathrm{~s}$ of $(\mathrm{CHI} / \mathrm{ALG})_{5}$ was used as an example of the nitrogen peak appearing after the deposition of chitosan.
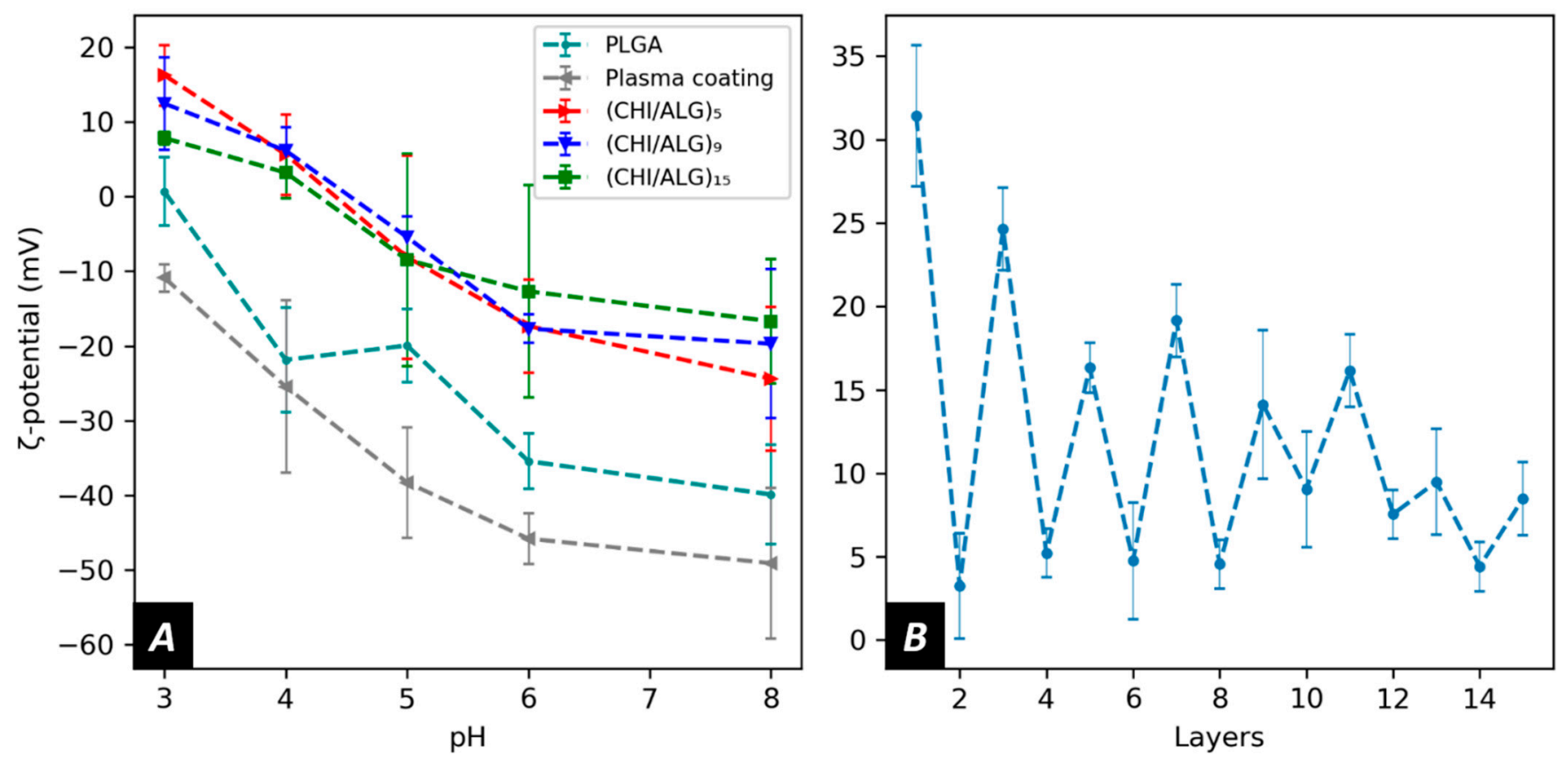

Figure 5. Surface zeta potential of (A) PLGA, plasma coated, (CHI/ALG) ${ }_{5},(\mathrm{CHI} / \mathrm{ALG})_{9},(\mathrm{CHI} / \mathrm{ALG})_{15}$, and (B) of the layer deposition process at $\mathrm{pH} 3$. 


\subsection{Drug Loading and Drug Release from the Chitosan/Alginates Modified Fibers \\ 3.2.1. Drug Loading}

The loading kinetics of IBU within the different meshes were evaluated and were $\mathrm{pH}$ responsive. The amount of drug loaded was evaluated at different $\mathrm{pH}$ values (2.0, 5.0, 7.0, and 10.0; see Figure 6). The loading of the mesh was done by immersing the fibers in a saturated solution of IBU in the aforementioned $\mathrm{pH}$ range. The highest amount of drug loaded within most of the meshes was at $\mathrm{pH} 2.0$, where $6.6 \pm 0.7,3.4 \pm 0.4$, and $3.1 \pm 1.0 \mu \mathrm{g} \cdot \mathrm{mg}^{-1}$ were loaded in the (CHI/ALG) $)_{5}$ (CHI/ALG) $)_{9}$ or (CHI/ALG) 15 meshes, respectively. An increasing number of layers lowered the amount of drug incorporated within the mesh for $\mathrm{pH} 2.0$ and 5.0 when comparing (CHI/ALG) $)_{5}$ with (CHI/ALG) 9 and $(\mathrm{CHI} / \mathrm{ALG})_{15}$ ( $p$-values $\left.<0.05\right)$, while for higher $\mathrm{pH}$, the amount of layer did not change the amount of drug loaded. The time-dependent loading curves are shown in Figure S7, and the drug penetrated the coating immediately, as the amount of drug loaded within the fibers did not change between $15 \mathrm{~m}$ and $24 \mathrm{~h}$. The drug loading efficiency and the drug content within the fibers calculated using Equations S1 and S2 and are shown in Table S2. For subsequent release experiments, the drug was loaded by immersing the fibers in $\mathrm{pH}$ 2.0 for $1 \mathrm{~h}$.

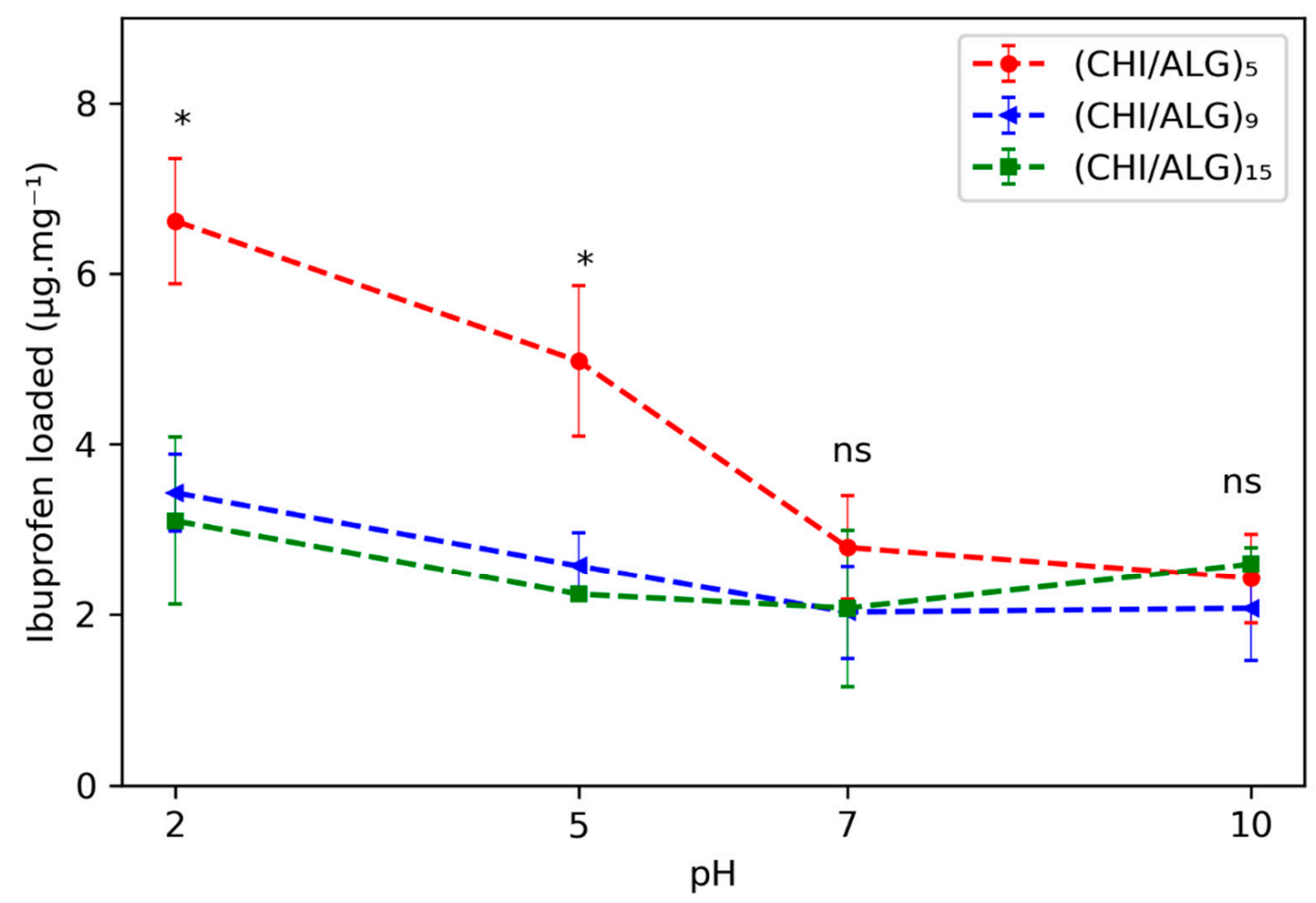

Figure 6. Amount of drug loaded onto the meshes pHs after $15 \mathrm{~m}$ of immersion in a saturated solution of IBU at $\mathrm{pH} 2.0,5.0$, 7.0, and 10.0. Statistical significance between $(\mathrm{CHI} / \mathrm{ALG})_{5}$ and $(\mathrm{CHI} / \mathrm{ALG})_{9}$ or $(\mathrm{CHI} / \mathrm{ALG})_{15}$ is highlighted with a and non-significant differences between amounts are indicated with text (ns).

\subsubsection{Drug Release}

The release of IBU from the meshes was measured in PBS at pH 7.4 and pH 5.5 as well as in SGF (pH 1.0, Figure 7). The release is depicted by a strong burst release, where most of the drug was released over $5 \mathrm{~h}$, followed by a more sustained release over a 3-day time span. No significant differences in the release kinetics were observed when adjusting PBS from $\mathrm{pH} 7.4$ to $\mathrm{pH} 5.5$ ( $p$-values $>0.1$ ). Nevertheless, IBU was delivered slower in acidic $\mathrm{pH}$ (SGF, pH 1.0, $p$-values < 0.05) when compared to the other two $\mathrm{pH}$ environments. The insets show the release curves during the first three hours. The number of layers added to the surface did not affect the kinetics of the release. The curves were fitted using the 
Ritger-Peppas model, which provides precious information concerning the diffusion from the mesh, and the values for the model can be found in Table S2.

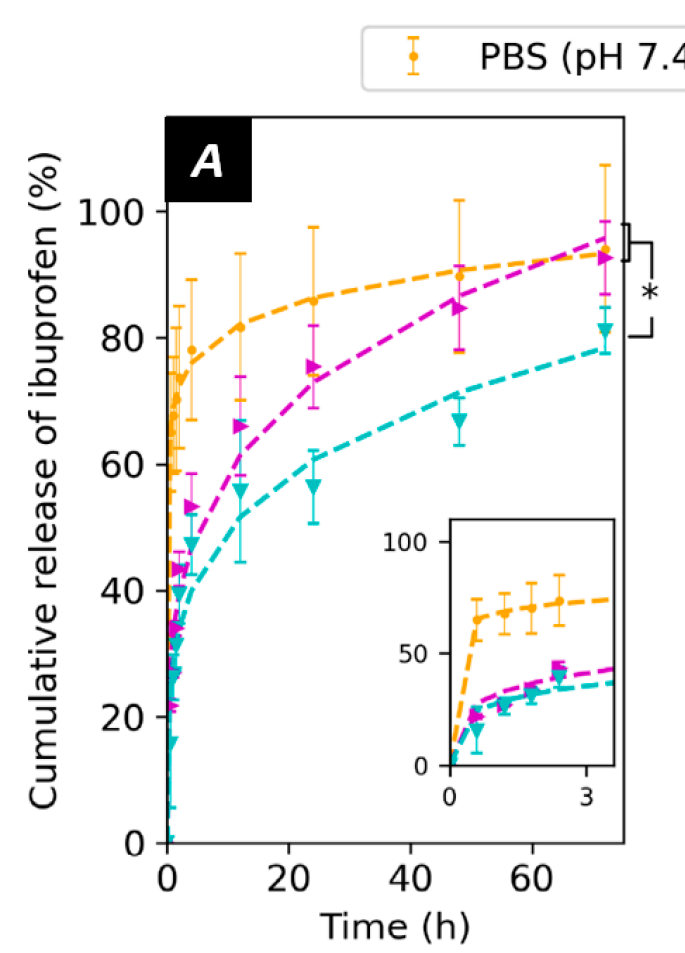

$(\mathrm{CHI} / \mathrm{ALG})_{5}$

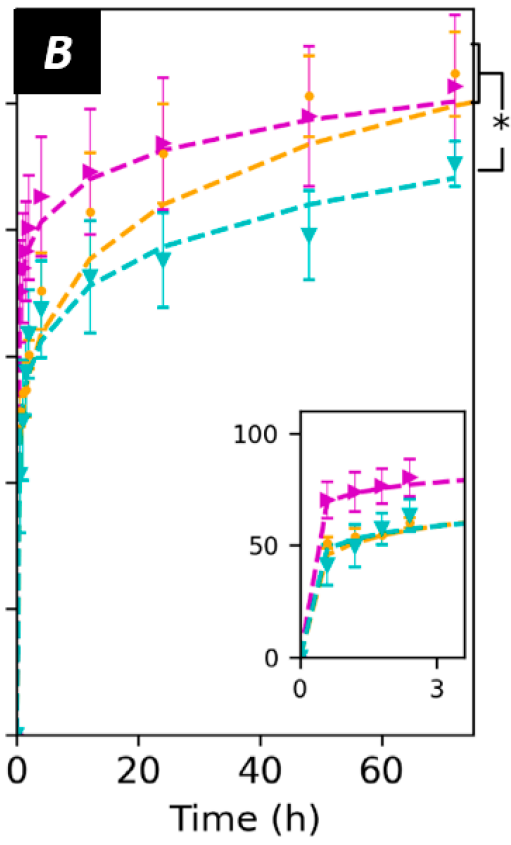

$(\mathrm{CHI} / \mathrm{ALG})_{9}$
SGF (pH 1.0)

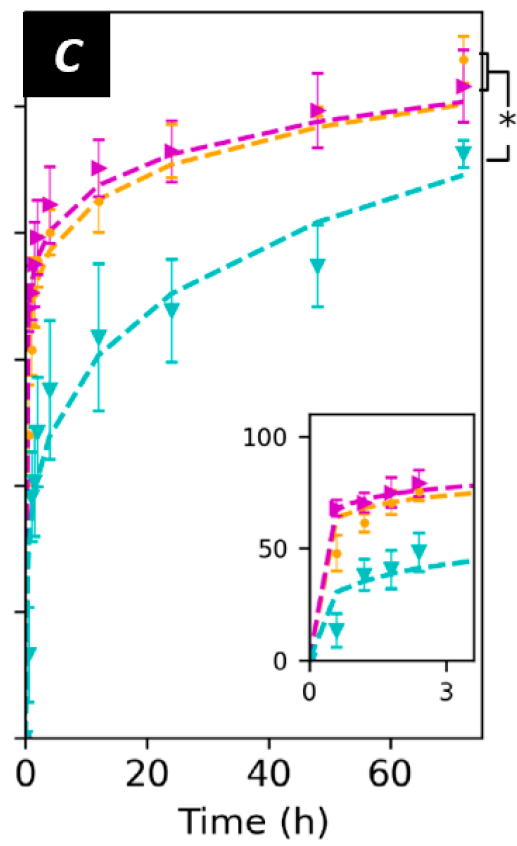

$(\mathrm{CHI} / \mathrm{ALG})_{15}$

Figure 7. Drug release in PBS (pH 7.4), PBS adjusted to pH 5.5 and SGF (pH 1) from (A) (CHI/ALG)5, (B) (CHI/ ALG)9, and $(\mathrm{C})(\mathrm{CHI} / \mathrm{ALG})_{15}$. The release rates were fitted using the Ritger-Peppas (power law) model. Statistical significance is indicated with * when comparing the release PBS ( $\mathrm{pH} 7.4)$ and PBS (pH 5.0) with the release in SGF(pH 1.0).

\section{Discussion}

Electrospinning of PLGA is well documented in the literature, and several studies show the impact of solvent and electrospinning conditions on the resulting nanofibers [51-53]. The fibers obtained by directly electrospinning PLGA dissolved in THF/DMF were in the microscale, while, to fully exploit the high surface-to-volume ratio of the mesh, fibers in the nanoscale were desired. Adding $0.01 \%(w / v)$ BTEAC to the polymer solution resulted in higher electrical conductivity, leading to nanoscopic fibers, as previously reported [54]. PLGA nanofibers exhibited a smooth surface and were bead-free, as shown in the SEM pictures (Figure 2). The grafting of $\mathrm{CHI}$ onto the surface of pure PLGA nanofibers proved to be unsuccessful. The negative surface charge of PLGA was insufficient to generate robust electrostatic interactions with CHI. To solve this issue, the nanofibers were submitted to a plasma gradient to lower the charge of the mesh as described in previous work [42].

Electrospun meshes are composed of several layers of fibers stacked on each other, forming a mesh that can reach several micrometers in thickness. The usual immersion coating on electrospun nanofibers is done by simply soaking the mat in a polymer solution. We found that by forcing the solution through the pores of the mesh using a Büchner filter directly connected to a high vacuum pump, a more homogeneous coating of the inner layers of nanofibers was achieved (data not shown here). This can be explained by a better interaction of the polymer solution with the different layers of the electrospun mesh as compared to simple immersion coating where the solution needs to penetrate through the mesh only via mechanical agitation. The rinsing steps were also performed using a Büchner filter to remove excess polysaccharides. 
Using this approach, CHI and ALG were sequentially deposited onto the surface of the nanofibers to produce five, nine, and 15 layers, where the last layer was always CHI. ALG was used as a polyanionic entity to form the polyelectrolyte complex onto the surface and provided better cohesion throughout the coating. The surface morphology of the nanofibers appeared more granular after the LbL coating as described previously in the literature $[29,37,55]$. The pores appeared to be filled with polysaccharide after the deposition of nine and 15 layers, where the polyelectrolyte complexes covered the pores of the membrane, confirming previous findings $[37,55]$. This occurred throughout the whole membrane, as observed in the cross-section image (Figure 2F). A possible explanation could be the aggregation of the polyelectrolyte complex onto the surface throughout the coating steps or the splitting of the coated film into webs during the drying step. The lower magnification images in Figure S2 further show this phenomenon and the poor homogeneity of the coating on the meshes.

Further characterization using AT-FTIR confirmed the deposition of the polysaccharides on the surface of the electrospun nanofibers. The typical bands for the -NH bending vibration of the $-\mathrm{NH}_{2}$ amino group contained in $\mathrm{CHI}$ could be observed after the LbL assembly (Figure 1B). The penetration depth of infrared lying in the range of several micrometers confirms the successful deposition of the polysaccharides throughout the mesh.

Moreover, XPS was used to determine the surface composition of the electrospun nanofibers. The spectrum of PLGA exhibited the regular peaks for the polyester, and the peak fitting was in accordance with previous literature. After plasma coating, the shape of the carbon peak changed due to the incorporation of novel oxygen species on the surface. Furthermore, after coating the electrospun nanofibers via LbL, a clear peak appeared in the region of 396-404 eV. This peak can be attributed to the electrons emitted by the primary amines within the structure of $\mathrm{CHI}$, and the nitrogen content appeared to be the same as the pure CHI powder (Figure S6). This validates that the CHI layers entirely cover the surface of the electrospun nanofibers.

To study the evolution of the surface charge during the coating, the $\zeta$-potential of the meshes was measured using the streaming potential technique. The $\zeta$-potential of pure PLGA electrospun nanofibers was negative over the measured $\mathrm{pH}$ range. This can be explained by the physical chemistry of polyesters, which have low $\mathrm{pH}$ isoelectric points, negatively charged ester groups, as well as negatively charged carboxylic end groups in their polymeric backbones. At higher $\mathrm{pH}$, the $\zeta$-potential of PLGA diminishes due to the dissociation of the carboxylic groups. After plasma treatment, the $\zeta$-potential decreased, allowing the deposition of positively charged $\mathrm{CHI}$ onto the fibers.

The LbL assembly was performed at $\mathrm{pH} 5.0$ to favor interaction between the dissolved polysaccharides as both $\mathrm{CHI}$ and ALG were charged at this $\mathrm{pH}$. After depositing the first layer of $\mathrm{CHI}$, the surface $\zeta$-potential became positive in an acidic $\mathrm{pH}$ environment. The negatively charged carboxylic acid on alginate's polymeric backbone led to a decrease in $\zeta$-potential when ALG was added. The polyelectrolytes used for this study are oppositely charged, but no charge reversal was observed when adding ALG onto the surface. Such findings can be explained by the different charge densities of the polysaccharide used in our study [56]. Furthermore, as more layers were added, the change in surface charge became less evident (Figure 5B). This could be explained by the strong interactions within the polyelectrolyte complexes lowering the surface charge as most of the charges within the coating were screened by the oppositely charged polyelectrolyte.

After highlighting the presence of the polysaccharides on the surface of the electrospun nanofibers, we measured the capacity of the fibers to act as a drug delivery system by measuring their loading and release capacity. To evaluate the loading capacity of the coated electrospun meshes, we used UHPLC to follow the concentration of a saturated drug solution after immersing meshes of known weights. UHPLC provides an exceptional tool to detect IBU in solution, as the detection limit was accurate down to $20 \mathrm{ng} \cdot \mathrm{mL}^{-1}$ and the separation over the column prevented any other compounds from interfering with 
the measurement. When studying the drug loading, more IBU penetrated the coating at $\mathrm{pH} 2.0$ when compared to other $\mathrm{pH}$ values for most of the meshes (Figure 6). This can be explained by the protonation of the amino function of the $\mathrm{CHI}$ within the coating that allowed for better electrostatic interactions with IBU, which possesses a carboxylic acid in its structure.

It is noteworthy that the loading of the drug into the mesh was instantaneous, as the first time point was taken at 15 minutes, and the quantity of drug within the supernatant did not significantly change afterwards, regardless of the $\mathrm{pH}$ and the number of layers (Figure S7). We also found that (CHI/ALG) ${ }_{9}$ and (CHI/ALG) ${ }_{15}$ exhibited a lower amount of drug loaded at low $\mathrm{pH}(2.0$ and 5.0) than (CHI/ALG) 5 , while the same amount of drug was loaded at higher $\mathrm{pH}$ (7.0 and 10.0) (Figure 6). As previously mentioned, when the number of polysaccharide layers stacked onto the surface increased, the electrostatic force from the resulting system diminished due to charge screening from the other layers. Therefore, the aforementioned interaction between $\mathrm{CHI}$ and IBU was disrupted as more layers were added, hence explaining the lower loading rates. Another phenomenon explaining the lower loading was the surface area diminishing with the increasing number of layers limiting the diffusion of drug molecules into the mesh. Due to the high amount of drug loaded at $\mathrm{pH}$ 2.0, this $\mathrm{pH}$ was used to load the drug and study the release from the mesh.

Alongside the drug loading, the release of IBU from the mesh was $\mathrm{pH}$-sensitive. For all the measured samples, a strong burst release occurred, which can be associated with the desorption of IBU from the coating. In addition, the washing steps of the meshes in $\mathrm{pH}$-neutral MilliQ water after the incorporation of the drug might trigger and initiate the release, leading to faster diffusion of the drug molecules to the surface. It is noteworthy to consider that the drug was assumed to be homogeneously distributed throughout the coating and that the coating was also assumed to be homogeneous when measuring the amount of drug loaded within the mesh and therefore released. Such assumptions and the low amount of sample measured leads to a difficult interpretation of the results and high standard deviations. This is also the explanation of values in the release profile exceeding $100 \%$, as the amount of drug within the mesh could have been underestimated during the previous measurements.

After the burst release, significantly less drug was released from the mesh in acidic media (SGF, pH 1.0) than in PBS (pH 7.4 and 5.0). The pH-sensitive release can be explained by the existence of stronger interactions between IBU and the coating in an acidic environment, mainly between the protonated amino function of $\mathrm{CHI}$ and the carboxylic acid function of IBU. In addition, slower dissolution rates of IBU in acidic media could contribute to the observed kinetic rates [57]. When lowering the pH of PBS from 7.4 to 5.5, no significant changes could be observed in the release kinetics. This can be because not enough amino functions were protonated to interact and prevent the release of IBU. Furthermore, as suggested by the value of the release exponent $(n<0.5)$ of the Ritger-Peppas model, the release followed a diffusion-controlled mechanism [58,59]. The coefficient of determination values $(>0.95$, Table S2) also confirmed the validity of the model for the measured samples. Ibuprofen was chosen in this study as a model drug. Since the interactions between the coating and the drug regulate the release kinetics of the system, the use of other drugs will likely affect the release profile and offer different opportunities

Interestingly, the number of CHI/ALG layers onto the surface of the mesh did not affect the kinetics of the release. This was unexpected, as the $\zeta$-potential of the surface and the drug loading were different when adding more layers and therefore should alter the interactions between IBU and CHI. Finally, the amount of IBU loaded and released by the measured meshes was in the therapeutic range of the drug $\left(10-50 \mathrm{mg} . \mathrm{L}^{-1}\right)$ [60]. In terms of applications, the $\mathrm{pH}$-sensitive behavior of the meshes could prove to be a useful tool for the delivery of anti-inflammatory drugs required to pass through the digestive tracts known to have an acidic $\mathrm{pH}(1.0)$. Indeed, the proposed nanofibers could bypass the acidic environment of the stomach to allow for the delivery of therapeutics to the other part of 
the gastrointestinal tract [61]. For example, the jejunum or the ileum would be targets of choice for local delivery of ibuprofen using the fibers fabricated in this study.

\section{Conclusions}

In this study, we demonstrate the use of CHI/ALG coatings on electrospun nanofibers as a $\mathrm{pH}$-sensitive drug delivery system. This simple and efficient way to decorate electrospun meshes via LbL paves the way to sophisticated functionalization in order to introduce novel properties to electrospun meshes. Here, we showed that the addition of $\mathrm{CHI}$ and ALG onto the surface led to the introduction of $\mathrm{pH}$ sensitivity, while the substrate (PLGA) is known to be inert toward changes in the environmental $\mathrm{pH}$. While all materials used for this study have proven to be biocompatible in previous studies [62], further work involves the evaluation of the fabricated fibers in terms of biocompatibility. The grafting of materials onto the surface of electrospun fibers will be one of the major future directions for electrospinning as it allows for better biocompatibility, new functionalities, and the development of sophisticated systems.

Supplementary Materials: The following are available online at https://www.mdpi.com/article/ 10.3390/nano11071850/s1, Figure S1: Fiber distribution for (A) PLGA, (B) plasma coated, (C) $(\mathrm{CHI} / \mathrm{ALG})_{5}$, (D) $(\mathrm{CHI} / \mathrm{ALG})_{9}$, and (E) (CHI/ALG) ${ }_{15}$. Figure S2: SEM pictures showing the overview of (A) PLGA nanofibers, (B) plasma-coated nanofibers, (C) (CHI/ALG) ${ }_{5}$, (D) (CHI/ALG) $)_{9}$, and (E) $(\mathrm{CHI} / \mathrm{ALG})_{15}$. Figure S3: Typical chromatogram for ibuprofen $(0.0105 \mathrm{mg} / \mathrm{mL}$ in PBS). Figure S4: Calibration curves of ibuprofen in water at (A) pH 2, (B) pH 5, (C) pH 7, and (D) pH10. Figure S5: Calibration curves of ibuprofen in PBS ((A) pH 7.4 and (B) $\mathrm{pH} 5.5$ and in simulated gastric fluid (C) $\mathrm{pH}$ 1). Figure S6: XPS survey scan of (A) chitosan and (B) sodium alginate. Figure S7: Timedependent loading curves at (A) pH 2, (B) pH 5, (C) pH 7, and (D) pH 10. Table S1: Apex Track Integration Parameters for ibuprofen. Table S2: Loading efficiency and the drug content within the fibers for the different $\mathrm{pH}$ of the different samples. Equation $\mathrm{S} 1$ and Equation $\mathrm{S} 2$ were used for the determination of the loading efficiency and the drug content, respectively. Table S3-Ritger-Peppas model parameters. Equation S1: Drug-loading efficiency formula. Equation S2: Drug content in the fiber formula

Author Contributions: Conceptualization, J.S., R.M.R., K.W.-K., F.I., N.L. and G.F.; methodology, J.S. and S.G.; formal analysis, J.S, F.I., S.G. and G.F.; supervision, R.R, S.J.F., D.H., K.W.-K. and G.F., interpretation.; J.S., F.I., G.F. and R.M.R. writing-original draft preparation, all the authors participated in.; writing - review and conceptualization of the manuscript. Project administration, R.M.R. and G.F.; funding acquisition, R.M.R. and G.F. All authors have read and agreed to the published version of the manuscript.

Funding: J.S. and R.R would like to acknowledge the Novartis Research Foundation (grant "Virtual twinning for intelligent, personalized transdermal drug delivery") and the Swiss Competence Center for Materials Science and Technology (CCMX) for funding. The authors would like to dedicate this paper to the memory of Giuseppino Fortunato.

Data Availability Statement: The raw data of this paper are fully accessible on request to the authors.

Acknowledgments: The authors would like to thank Anne Géraldine Guex for reviewing and providing feedback on the manuscript.

Conflicts of Interest: The authors declare no conflict of interest. The funders had no role in the design of the study; in the collection, analyses, or interpretation of data; in the writing of the manuscript, or in the decision to publish the results.

\section{References}

1. Wang, Y.; Kotsuchibashi, Y.; Uto, K.; Ebara, M.; Aoyagi, T.; Liu, Y.; Narain, R. PH and Glucose Responsive Nanofibers for the Reversible Capture and Release of Lectins. Biomater. Sci. 2015, 3, 152-162. [CrossRef]

2. Li, H.; Liu, K.; Williams, G.R.; Wu, J.; Wu, J.; Wang, H.; Niu, S.; Zhu, L.M. Dual Temperature and PH Responsive Nanofiber Formulations Prepared by Electrospinning. Colloids Surf. B Biointerfaces 2018, 171, 142-149. [CrossRef]

3. Khatri, Z.; Ali, S.; Khatri, I.; Mayakrishnan, G.; Kim, S.H.; Kim, I.S. UV-Responsive Polyvinyl Alcohol Nanofibers Prepared by Electrospinning. Appl. Surf. Sci. 2015, 342, 64-68. [CrossRef] 
4. Meng, J.; Xiao, B.; Zhang, Y.; Liu, J.; Xue, H.; Lei, J.; Kong, H.; Huang, Y.; Jin, Z.; Gu, N.; et al. Super-Paramagnetic Responsive Nanofibrous Scaffolds under Static Magnetic Field Enhance Osteogenesis for Bone Repair in Vivo. Sci. Rep. 2013, 3, 2655. [CrossRef]

5. Abrigo, M.; McArthur, S.L.; Kingshott, P. Electrospun Nanofibers as Dressings for Chronic Wound Care: Advances, Challenges, and Future Prospects. Macromol. Biosci. 2014, 14, 772-792. [CrossRef] [PubMed]

6. Yuan, H.; Li, B.; Liang, K.; Lou, X.; Zhang, Y. Regulating Drug Release from PH- and Temperature-Responsive Electrospun CTS-g-PNIPAAm/Poly(Ethylene Oxide) Hydrogel Nanofibers. Biomed. Mater. 2014, 9, 055001. [CrossRef] [PubMed]

7. Kim, Y.-J.; Ebara, M.; Aoyagi, T. Temperature-Responsive Electrospun Nanofibers for 'on-off' Switchable Release of Dextran. Sci. Technol. Adv. Mater. 2012, 13, 64203. [CrossRef]

8. Ghavaminejad, A.; Sasikala, A.R.K.; Unnithan, A.R.; Thomas, R.G.; Jeong, Y.Y.; Vatankhah-Varnoosfaderani, M.; Stadler, F.J.; Park, C.H.; Kim, C.S. Mussel-Inspired Electrospun Smart Magnetic Nanofibers for Hyperthermic Chemotherapy. Adv. Funct. Mater. 2015, 25, 2867-2875. [CrossRef]

9. Demirci, S.; Celebioglu, A.; Aytac, Z.; Uyar, T. PH-Responsive Nanofibers with Controlled Drug Release Properties. Polym. Chem. 2014, 5, 2050-2056. [CrossRef]

10. González, E.; Frey, M.W. Synthesis, Characterization and Electrospinning of Poly(Vinyl Caprolactam-Co-Hydroxymethyl Acrylamide) to Create Stimuli-Responsive Nanofibers. Polymer 2017, 108, 154-162. [CrossRef]

11. Chuah, C.; Wang, J.; Tavakoli, J.; Tang, Y. Novel Bacterial Cellulose-Poly (Acrylic Acid) Hybrid Hydrogels with Controllable Antimicrobial Ability as Dressings for Chronic Wounds. Polymers 2018, 10, 1323. [CrossRef] [PubMed]

12. Watts, S.; Julian, T.R.; Maniura-Weber, K.; Graule, T.; Salentinig, S. Colloidal Transformations in MS2 Virus Particles: Driven by $\mathrm{PH}$, Influenced by Natural Organic Matter. ACS Nano 2020, 14, 1879-1887. [CrossRef] [PubMed]

13. Yuan, B.; Aziz, M.R.F.; Li, S.; Wu, J.; Li, D.; Li, R.-K. An Electro-Spun Tri-Component Polymer Biomaterial with Optoelectronic Properties for Neuronal Differentiation. Acta Biomater. 2021. [CrossRef] [PubMed]

14. Boda, S.K.; Fischer, N.G.; Ye, Z.; Aparicio, C. Dual Oral Tissue Adhesive Nanofiber Membranes for PH-Responsive Delivery of Antimicrobial Peptides. Biomacromolecules 2020, 21, 4945-4961. [CrossRef]

15. Weng, L.; Xie, J. Smart Electrospun Nanofibers for Controlled Drug Release: Recent Advances and New Perspectives. Curr. Pharm. Des. 2015, 21, 1944-1959. [CrossRef]

16. Makadia, H.K.; Siegel, S.J. Poly Lactic-Co-Glycolic Acid (PLGA) as Biodegradable Controlled Drug Delivery Carrier. Polymers 2011, 3, 1377-1397. [CrossRef]

17. Skaugrud, Ø.; Hagen, A.; Borgersen, B.; Dornish, M. Biomedical and Pharmaceutical Applications of Alginate and Chitosan. Biotechnol. Genet. Eng. Rev. 1999, 16, 23-40. [CrossRef]

18. Chaturvedi, K.; Ganguly, K.; More, U.A.; Reddy, K.R.; Dugge, T.; Naik, B.; Aminabhavi, T.M.; Noolvi, M.N. Sodium alginate in drug delivery and biomedical areas. In Natural Polysaccharides in Drug Delivery and Biomedical Applications; Elsevier: Amsterdam, The Netherlands, 2019; pp. 59-100. ISBN 9780128170557.

19. Qin, Y. Alginate Fibres: An Overview of the Production Processes and Applications in Wound Management. Polym. Int. 2008, 57, 171-180. [CrossRef]

20. Ravi Kumar, M.N.V. A Review of Chitin and Chitosan Applications. React. Funct. Polym. 2000, 46, 1-27. [CrossRef]

21. Gao, W.; Chan, J.M.; Farokhzad, O.C. PH-Responsive Nanoparticles for Drug Delivery. Mol. Pharm. 2010, 7, 1913-1920. [CrossRef] [PubMed]

22. Zhang, Y.; Tao, L.; Li, S.; Wei, Y. Synthesis of Multiresponsive and Dynamic Chitosan-Based Hydrogels for Controlled Release of Bioactive Molecules. Biomacromolecules 2011, 12, 2894-2901. [CrossRef]

23. Bhattarai, N.; Gunn, J.; Zhang, M. Chitosan-Based Hydrogels for Controlled, Localized Drug Delivery. Adv. Drug Deliv. Rev. 2010, 62, 83-99. [CrossRef] [PubMed]

24. Prabaharan, M.; Mano, J.F. Stimuli-Responsive Hydrogels Based on Polysaccharides Incorporated with Thermo-Responsive Polymers as Novel Biomaterials. Macromol. Biosci. 2006, 6, 991-1008. [CrossRef]

25. He, C.W.; Parowatkin, M.; Mailänder, V.; Flechtner-Mors, M.; Ziener, U.; Landfester, K.; Crespy, D. Sequence-Controlled Delivery of Peptides from Hierarchically Structured Nanomaterials. ACS Appl. Mater. Interfaces 2017, 9, 3885-3894. [CrossRef]

26. Berger, J.; Reist, M.; Mayer, J.M.; Felt, O.; Gurny, R. Structure and Interactions in Chitosan Hydrogels Formed by Complexation or Aggregation for Biomedical Applications. Eur. J. Pharm. Biopharm. 2004, 57, 35-52. [CrossRef]

27. Gierszewska, M.; Ostrowska-Czubenko, J.; Chrzanowska, E. PH-Responsive Chitosan/Alginate Polyelectrolyte Complex Membranes Reinforced by Tripolyphosphate. Eur. Polym. J. 2018, 101, 282-290. [CrossRef]

28. Xie, J.; Michael, P.L.; Zhong, S.; Ma, B.; MacEwan, M.R.; Lim, C.T. Mussel Inspired Protein-Mediated Surface Modification to Electrospun Fibers and Their Potential Biomedical Applications. J. Biomed. Mater. Res. Part A 2012, 100 A, 929-938. [CrossRef]

29. Lin, C.C.; Fu, S.J.; Lin, Y.C.; Yang, I.K.; Gu, Y. Chitosan-Coated Electrospun PLA Fibers for Rapid Mineralization of Calcium Phosphate. Int. J. Biol. Macromol. 2014, 68, 39-47. [CrossRef] [PubMed]

30. Delcea, M.; Möhwald, H.; Skirtach, A.G. Stimuli-Responsive LbL Capsules and Nanoshells for Drug Delivery. Adv. Drug Deliv. Rev. 2011, 63, 730-747. [CrossRef]

31. Wang, Y.; Ma, B.; Yin, A.; Zhang, B.; Luo, R.; Pan, J.; Wang, Y. Polycaprolactone Vascular Graft with Epigallocatechin Gallate Embedded Sandwiched Layer-by-Layer Functionalization for Enhanced Antithrombogenicity and Anti-Inflammation. J. Control. Release 2020, 320, 226-238. [CrossRef] [PubMed] 
32. Richardson, J.J.; Cui, J.; Björnmalm, M.; Braunger, J.A.; Ejima, H.; Caruso, F. Innovation in Layer-by-Layer Assembly. Chem. Rev. 2016, 116, 14828-14867. [CrossRef] [PubMed]

33. Park, S.; Han, U.; Choi, D.; Hong, J. Layer-by-Layer Assembled Polymeric Thin Films as Prospective Drug Delivery Carriers: Design and Applications. Biomater. Res. 2018, 22, 29. [CrossRef] [PubMed]

34. Zhang, X.; Liang, T.; Ma, Q. Layer-by-Layer assembled nano-drug delivery systems for cancer treatment. Drug Deliv. 2021, 28, 655-669. [CrossRef]

35. Croisier, F.; Sibret, P.; Dupont-Gillain, C.C.; Genet, M.J.; Detrembleur, C.; Jérôme, C. Chitosan-Coated Electrospun Nanofibers with Antibacterial Activity. J. Mater. Chem. B 2015, 3, 3508-3517. [CrossRef]

36. Deng, H.; Zhou, X.; Wang, X.; Zhang, C.; Ding, B.; Zhang, Q.; Du, Y. Layer-by-Layer Structured Polysaccharides Film-Coated Cellulose Nanofibrous Mats for Cell Culture. Carbohydr. Polym. 2010, 80, 474-479. [CrossRef]

37. Fortunato, G.; Guex, A.G.; Popa, A.M.; Rossi, R.M.; Hufenus, R. Molecular Weight Driven Structure Formation of PEG Based E-Spun Polymer Blend Fibres. Polymer 2014, 55, 3139-3148. [CrossRef]

38. Schneider, C.A.; Rasband, W.S.; Eliceiri, K.W. NIH Image to ImageJ: 25 Years of Image Analysis. Nat. Methods 2012, 9, 671-675. [CrossRef]

39. Guex, A.G.; Kocher, F.M.; Fortunato, G.; Körner, E.; Hegemann, D.; Carrel, T.P.; Tevaearai, H.T.; Giraud, M.N. Fine-Tuning of Substrate Architecture and Surface Chemistry Promotes Muscle Tissue Development. Acta Biomater. 2012, 8, 1481-1489. [CrossRef]

40. Körner, E.; Fortunato, G.; Hegemann, D. Influence of RF Plasma Reactor Setup on Carboxylated Hydrocarbon Coatings. Plasma Process. Polym. 2009, 6, 119-125. [CrossRef]

41. Guex, A.G.; Hegemann, D.; Giraud, M.N.; Tevaearai, H.T.; Popa, A.M.; Rossi, R.M.; Fortunato, G. Covalent Immobilisation of VEGF on Plasma-Coated Electrospun Scaffolds for Tissue Engineering Applications. Colloids Surf. B Biointerfaces 2014, 123, 724-733. [CrossRef] [PubMed]

42. Hegemann, D.; Indutnyi, I.; Zajíčková, L.; Makhneva, E.; Farka, Z.; Ushenin, Y.; Vandenbossche, M. Stable, Nanometer-Thick Oxygen-Containing Plasma Polymer Films Suited for Enhanced Biosensing. Plasma Process. Polym. 2018, 15, 1800090. [CrossRef]

43. Peppas, N.A.; Narasimhan, B. Mathematical Models in Drug Delivery: How Modeling Has Shaped the Way We Design New Drug Delivery Systems. J. Control. Release 2014, 190, 75-81. [CrossRef]

44. Ritger, P.L.; Peppas, N.A. A Simple Equation for Description of Solute Release I. Fickian and Non-Fickian Release from NonSwellable Devices in the Form of Slabs, Spheres, Cylinders or Discs. J. Control. Release 1987, 5, 23-36. [CrossRef]

45. Peppas, N. Chemical and Physical Structure of Polymers as Carriers for Controlled Release of Bioactive Agents: A Review. J. Macromol. Sci. Part C 1983, 23, 61-126. [CrossRef]

46. R Core Team. R: A Language and Environment for Statistical Computing; R Core Team: Vienna, Austria, 2021.

47. Vandenbossche, M.; Gunkel-Grabole, G.; Car, A.; Bernard, L.; Rupper, P.; Maniura-Weber, K.; Heuberger, M.; Faccio, G.; Hegemann, D. Near-Surface Structure of Plasma Polymer Films Affects Surface Behavior in Water and Its Interaction with Proteins. Plasma Chem. Plasma Process. 2018, 38, 851-870. [CrossRef]

48. Chen, M.; Gao, S.; Dong, M.; Song, J.; Yang, C.; Howard, K.A.; Kjems, J.; Besenbacher, F. Chitosan/SiRNA Nanoparticles Encapsulated in PLGA Nanofibers for SiRNA Delivery. ACS Nano 2012, 6, 4835-4844. [CrossRef]

49. Wang, Y.; Li, P.; Kong, L. Chitosan-Modified PLGA Nanoparticles with Versatile Surface for Improved Drug Delivery. AAPS PharmSciTech 2013, 14, 585-592. [CrossRef] [PubMed]

50. Kwak, S.; Haider, A.; Gupta, K.C.; Kim, S.; Kang, I.K. Micro/Nano Multilayered Scaffolds of PLGA and Collagen by Alternately Electrospinning for Bone Tissue Engineering. Nanoscale Res. Lett. 2016, 11, 323. [CrossRef]

51. Duan, B.; Yuan, X.; Zhu, Y.; Zhang, Y.; Li, X.; Zhang, Y.; Yao, K. A Nanofibrous Composite Membrane of PLGA-Chitosan/PVA Prepared by Electrospinning. Eur. Polym. J. 2006, 42, 2013-2022. [CrossRef]

52. Meng, Z.X.; Wang, Y.S.; Ma, C.; Zheng, W.; Li, L.; Zheng, Y.F. Electrospinning of PLGA/Gelatin Randomly-Oriented and Aligned Nanofibers as Potential Scaffold in Tissue Engineering. Mater. Sci. Eng. C 2010, 30, 1204-1210. [CrossRef]

53. You, Y.; Lee, S.J.; Min, B.M.; Park, W.H. Effect of Solution Properties on Nanofibrous Structure of Electrospun Poly(Lactic-CoGlycolic Acid). J. Appl. Polym. Sci. 2006, 99, 1214-1221. [CrossRef]

54. Xu, G.R.; Liu, X.Y.; Xu, J.M.; Li, L.; Su, H.C.; Zhao, H.L.; Feng, H.J. High Flux Nanofiltration Membranes Based on Layer-by-Layer Assembly Modified Electrospun Nanofibrous Substrate. Appl. Surf. Sci. 2018, 434, 573-581. [CrossRef]

55. Mohamad, H.S.; Neuber, S.; Helm, C.A. Surface Forces of Asymmetrically Grown Polyelectrolyte Multilayers: Searching for the Charges. Langmuir 2019, 35, 15491-15499. [CrossRef] [PubMed]

56. Tsume, Y.; Langguth, P.; Garcia-Arieta, A.; Amidon, G.L. In Silico Prediction of Drug Dissolution and Absorption with Variation in Intestinal PH for BCS Class II Weak Acid Drugs: Ibuprofen and Ketoprofen. Biopharm. Drug Dispos. 2012, 33, 366-377. [CrossRef]

57. Piccirillo, G.; Carvajal Berrio, D.A.; Laurita, A.; Pepe, A.; Bochicchio, B.; Schenke-Layland, K.; Hinderer, S. Controlled and Tuneable Drug Release from Electrospun Fibers and a Non-Invasive Approach for Cytotoxicity Testing. Sci. Rep. 2019, 9, 1-10. [CrossRef] [PubMed]

58. Baker, R.W.; Sanders, L.M. Controlled Release Delivery Systems. In Synthetic Membranes: Science, Engineering and Applications; Springer: Berlin, Germany, 1986; pp. 581-624.

59. Mazaleuskaya, L.L.; Theken, K.N.; Gong, L.; Thorn, C.F.; Fitzgerald, G.A.; Altman, R.B.; Klein, T.E. PharmGKB Summary: Ibuprofen Pathways. Pharmacogenet. Genom. 2015, 25, 96-106. [CrossRef] 
60. Hua, S. Advances in Oral Drug Delivery for Regional Targeting in the Gastrointestinal Tract-Influence of Physiological, Pathophysiological and Pharmaceutical Factors. Front. Pharmacol. 2020, 11, 524. [CrossRef] [PubMed]

61. Soscia, D.A.; Raof, N.A.; Xie, Y.; Cady, N.C.; Gadre, A.P. Antibiotic-Loaded PLGA Nanofibers for Wound Healing Applications. Adv. Eng. Mater. 2010, 12, B83-B88. [CrossRef]

62. Hu, W.W.; Yu, H.N. Coelectrospinning of Chitosan/Alginate Fibers by Dual-Jet System for Modulating Material Surfaces. Carbohydr. Polym. 2013, 95, 716-727. [CrossRef] 